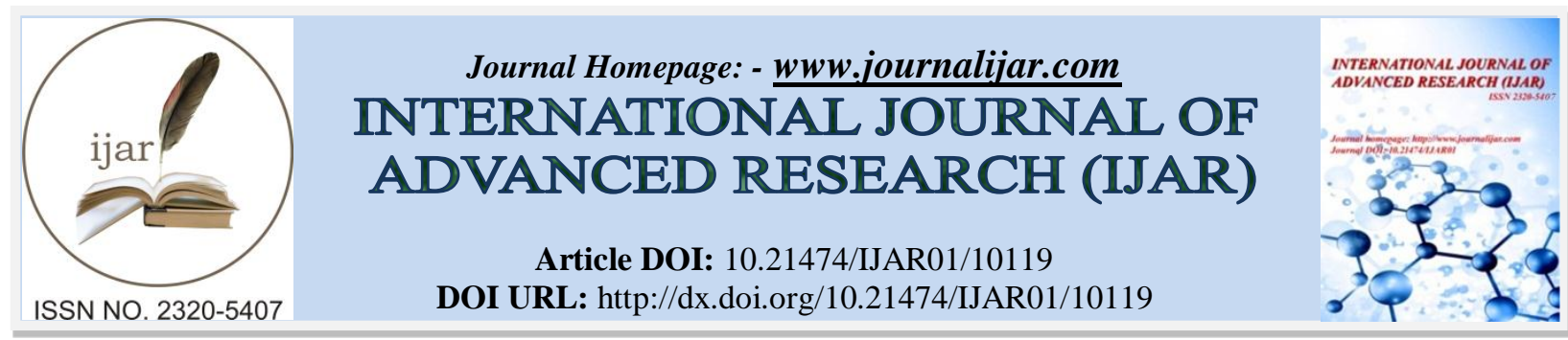

RESEARCH ARTICLE

\title{
FACTORS THAT INFLUENCE IN SCHOOL DROPOUT IN HIGHER EDUCATION STUDENTS FROM A PERSPECTIVE.
}

\author{
Arisveth Guadalupe Alejandro Dorantes ${ }^{1}$ and Ana Rosa Can Valle ${ }^{2}$. \\ 1. Intern of the Master in Educational Management of the National Pedagogic University. \\ 2. Professor and researcher of the Faculty of Nursing of the Autonomous University of Campeche.
}

\section{Manuscript Info}

Manuscript History

Received: 01 October 2019

Final Accepted: 03 November 2019

Published: December 2019

\begin{abstract}
School dropout is considered as the abandonment of the educational system by students, caused by a combination of factors that are generated both in school and in social contexts, family and individual contexts. Dropping out of school implies a definitive abandonment of an institution or a University, after having enrolled and therefore cannot finish the degree or level of study.

Objective: Identify the causes that influence school dropout and propose strategies to address the interest of the student.

Method: This research has a qualitative, descriptive, non-exploratory approach.

Subjects: 52 students of higher education.

Instrument: The questionnaire was applied to the survey for students about dropout in higher education.

Results: Of the participants, 29\% (15) are male and 71\% (37) are female students. When referring to you, what is school dropout for you?, $77 \%$ of the students think it is an educational problem that affects the development of the country, $17 \%$ commented that for them it is a psychosocial problem and 6\% refer That is a complex problem. When asking the students that they will do the next semester, $81 \%$ commented that they will continue with their studies and 19\% said they will change their degree.

Conclusion: The factors that influence school dropout can be mentioned what students think the economic factor considers as a dropout factor, $62 \%$ think that crime is also another factor, $71 \%$ think that with the support of a scholarship, Having good friendships and a good family relationship consider it a motivation to continue studying.
\end{abstract}

Copy Right, IJAR, 2019,. All rights reserved.

\section{Introduction:-}

School dropout is determined as the abandonment of the educational system by students, caused by a combination of factors that can be modified both in school and in social, family and individual contexts. Dropping out of school implies a permanent abandonment of an institution or a University, after having enrolled and therefore cannot complete the degree or level of study.

Corresponding Author:-Arisveth Guadalupe Alejandro Dorantes.

Address:-Intern of the Master in Educational Management of the National Pedagogic University. 
School dropout is a socio-educational problem, and refers to the mass of students who have dropped out of their studies at any time during the school year. This completely irregular, repeated and discontinuous assistance is maintained in some, others are definitely absent. This occurs in all populations where schools operate and cause serious damage to the normal development of the educational process and to the regular functioning of schools in a general way. School dropout is a socio-educational problem, and refers to the mass of students who have dropped out of their studies at any time during the school year. This completely irregular, repeated and discontinuous assistance is maintained in some, others are definitely absent. This occurs in all populations where schools operate and cause serious damage to the normal development of the educational process and to the regular functioning of schools in a general way.

A first definition found is that proposed by Bachman, Green and Wirtanen (2009). These authors point out that dropouts are caused by those students who interrupted their attendance at school for several weeks for different reasons, different only to those due to illness. Morrow (1986) broadens the definition by making it more rigorous: dropout is considered as an event that occurs when a student who was previously enrolled in school, left it for an extended period of time and did not enroll in another school.

Franklin and Kochan (2000) narrow the concept, identify a deserter as a student who enrolled in school at some point in the previous year and did not enroll at the beginning of the current year, having left unfinished preparation and without having been transferred to another school.

Bunn (2002, cited by Martinez, J.) described the dropout in a similar way, but in addition to the above, not only accepts the education system as the only formal way of educating, but also accepts the tutoring system by parents or private as a substitute for school.

Taking up the research carried out by Aros and Quezada (2003). in "adolescence and dropout" establishes that from the strictly educational perspective, the main factors that influence school dropout are related to: school organization, pedagogical practices, ways of living together, discipline, learning difficulties, lack of attention to the diversity of interests of the students and as one of the main factors repeating; The repeater is about $20 \%$ more likely to leave the school system. So some school factors increase the risk of school dropout or failure at school.

Tinto (1989) tells us that dropping out is an act that results from an emotional response of the individual, therefore, in order to understand this phenomenon it is imperative to identify the factors that influence the student's decision upon leaving school. Several studies carried out in different countries (2012), conclude that the phenomenon of desertion is the result of a multitude of factors, which makes it difficult to establish a direct causality.

To order and classify the conditions that affect dropout, Marcela Román (2013) developed a matrix of analysis of factors associated with school dropout and divides them into two main aspects: extracurricular factors: which include those that escape the direct influence of the educational community; Intra-school factors: which are those of the educational systems and the school organization, which hinder the achievement and permanence of students in school.

On the other hand, under the same line, Tinto (1989) considers that the student enters the institution with a certain objective in mind and that during his stay in the career, he goes through certain changes of personality and ideas as well as objectives, which sometimes It can lead to losing interest in their academic development, it indicates that the student is transformed by variable causes and divides the factors associated with desertion into five main categories: Psychological, social, economic, organizational, interactional.

\section{University dropout:}

Today we want to reflect on a fundamental issue in Mexico, we are referring to university dropout, this is everyone's problem. Based on studies conducted by the OECD (Organization for Economic Cooperation and Development), of the member countries of that organization, Mexico shares with Turkey the first place in the abandonment of university students. Based on data from INEGI, in Mexico only eight out of every 100 students conclude a university degree, the main reason is the lack of financial resources (Gracia, M. (2015).

The school dropout not only impacts the young person who leaves the degree, it also affects their families and in general the economy of the country. If young people do not finish a university career, it is logical that there is a 
smaller number of professionals, the above means that we will be less prepared in front of countries with a greater number of professionals by number of inhabitants. University dropout is multifactorial. The most frequent causes of university dropout are caused by economic, family, health, maternity, indiscipline, school or home changes, poor performance, work issues or academic dissatisfaction (Gracia, M. (2015).

School dropout can be defined according to the following authors:-

1. An imbalance between the needs of the student and the satisfiers that he finds in the university environment (Leon Festinger, 1962);

2. Flannery, J. et. al (1973). A discrepancy between expectations and student achievement.

3. A weakening of the commitment and initial expectations that the student has with the institutional community and the university environment in general (V. Tinto, 1975; W.G. Spady, 1971; P.T. Terenzini and E.T. Pascarella, 1979).

4. Mismatch between personality types and environmental types (J.L. Holland, 1966).

\section{Higher Education in Mexico:}

The university was one of the first institutions that was created after the conquest. At present, Higher Education is conceived as a vital instrument for the modernization of Mexico.

The society of the beginning of the next century will generate a set of challenges of enormous magnitude of IES that, at the same time, will open new opportunities for their development and consolidation and for their greater contribution to the construction of a country in which it is expected that their men and women of all ages and from all regions, have improved their living conditions in the economic, social, political and cultural. In the field in the development of higher education is related to the scientific and technological revolution that is lived on the planet. The geometric progression of the collections of scientific and technological knowledge and of the new information and communication technologies present multiple opportunities for the development of higher education. The greater interaction between the academic communities allows a continuous process of the processes of improvement of the educational quality.

Higher education of the future will be a gateway to the knowledge society, perhaps the most important door because of its pre-compromised situation for the generation and transmission of human knowledge. In the knowledge society, education is conceived as an integral process without temporal limitations of age, level or school establishment. (Higher Education in the 21st Century).

\section{Method:-}

The objective of this investigation is identify the causes that influence school dropout and propose strategies to address the interest of the student. This research has a qualitative approach, descriptive type, these studies serve to specify important properties of people, groups, communities or any other phenomenon that is subjected to analysis, not experimental. The sample consisted of 52 university students male gender 29\% (15) and female gender $71 \%$ (37), the survey was applied for students about school dropout in higher education, in 15 multiple choice questions (author. KATHERUIZ), Students were explained how they should answer the survey. The database in the Microsoft Excel program was analyzed and the following results were obtained.

\section{Results:-}

After analyzing the data, the following results are presented below. 


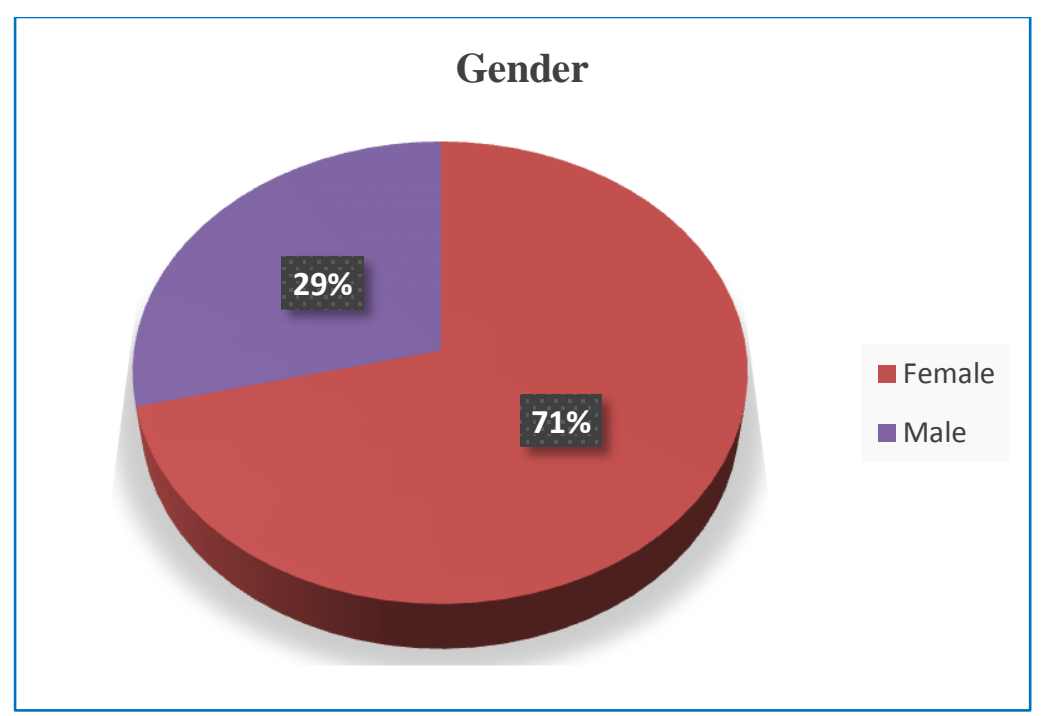

Graph 1:- Gender of the participants, 29\% (15) are male and 71\% (37) are female students (see graph 1)

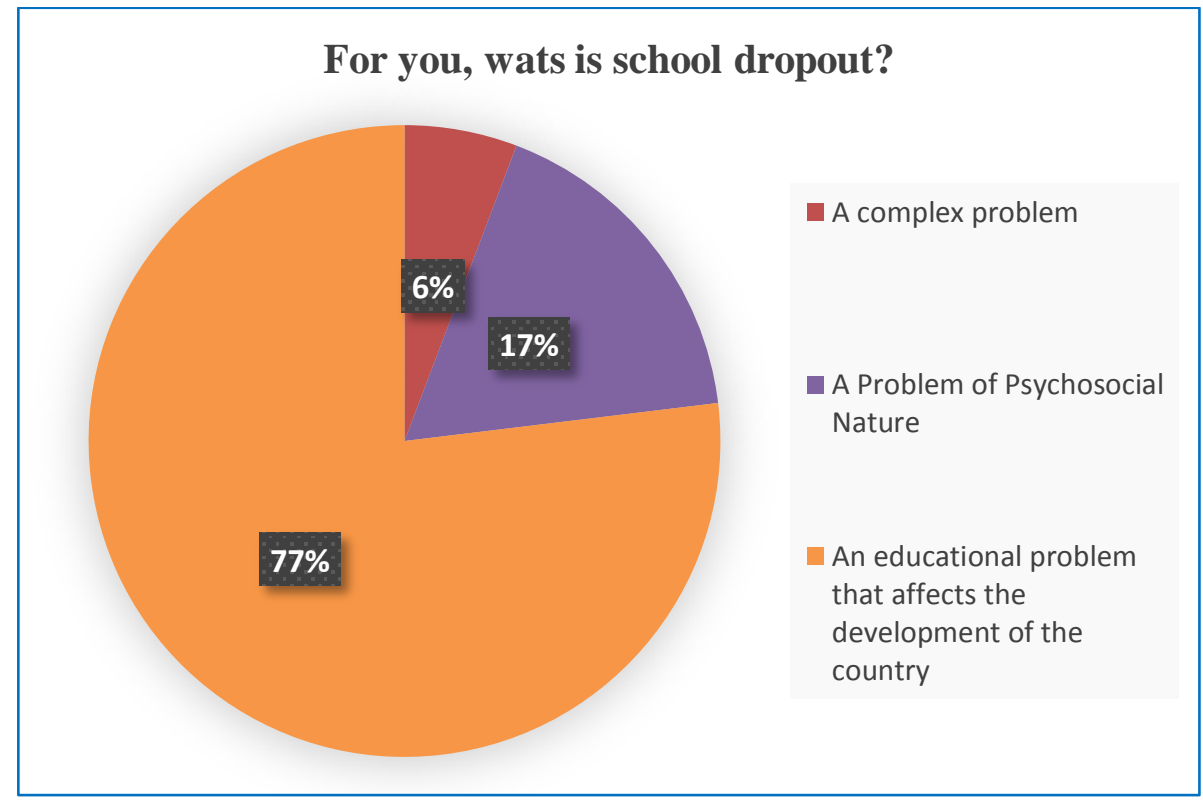

Graph 2:-For you, which is school dropout

When referring to graph 2, for you, which is school dropout, $77 \%$ of the students think it is an educational problem that affects the development of the country, $17 \%$ commented that for them it is a psychosocial problem and $6 \%$ say it is a complex problem. Dropping out of school is a socio-educational problem, and refers to the mass of students who have dropped out of school at any time during the school year. 


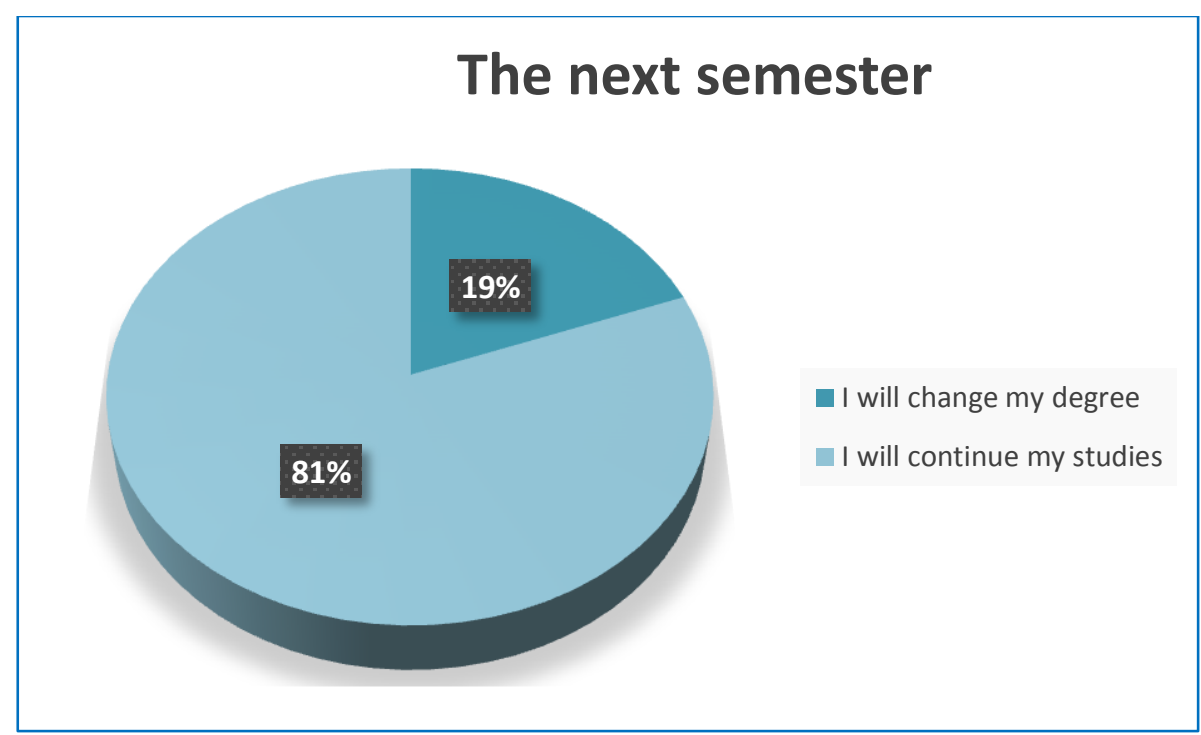

Graph 3:- The next semester when asking the students that they will do the next semester, $81 \%$ commented that they will continue their studies and 19\% thought they will change their degree, sometimes the students do not feel confident in the profession they chose and decide to change to another career (see graph 3).

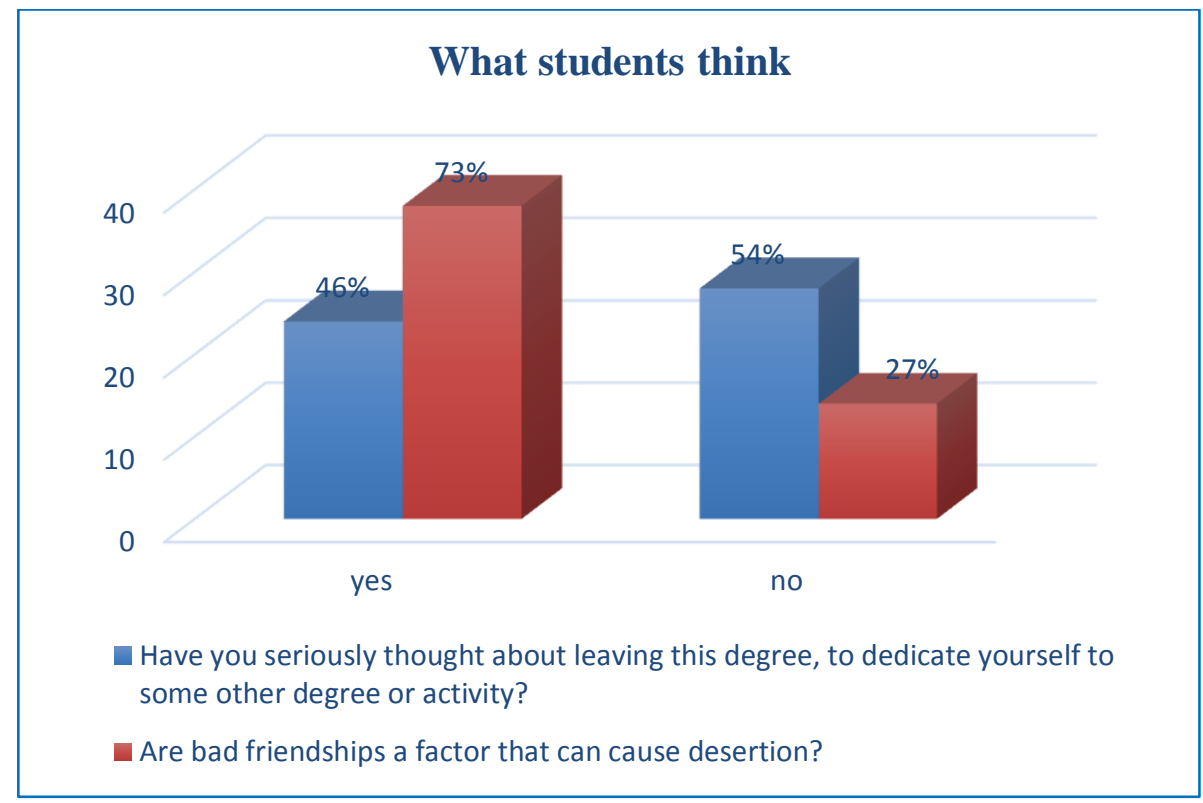

Graph 4:- What students think

In graph 4, what do the students think, have you seriously thought about dropping out of this degree, to dedicate yourself to some other degree or another activity? 24\% said yes and $28 \%$ said no. In the question are bad friendships a factor that can cause desertion? $38 \%$ said yes and $14 \%$ said no. 


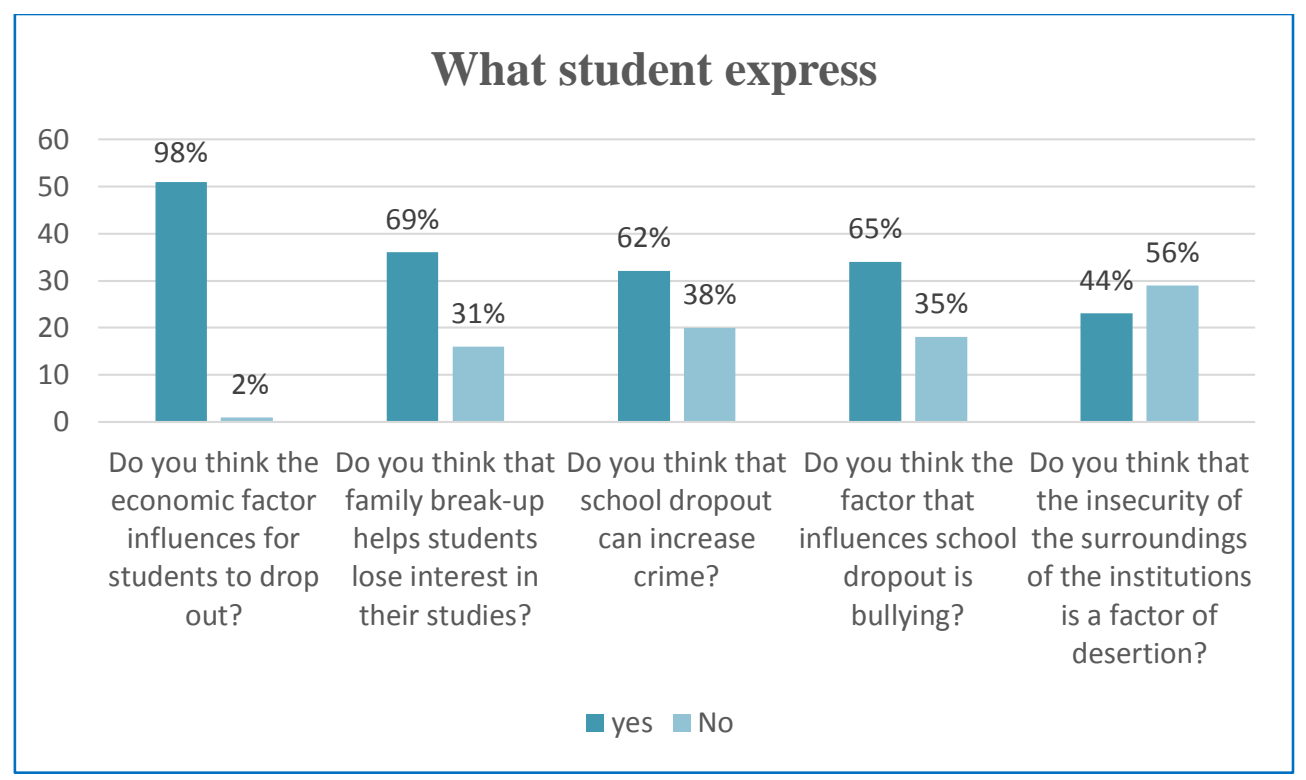

Graph 5:-The estudents express

In graph 5 where students are asked, do you think that the economic factor influences students to drop out? 98\% of students said yes and $2 \%$ said no; in the question, do you consider that the disintegration of the family helps students to gain interest in their studies? $69 \%$ consider yes and $31 \%$ say no; in the question that was asked to the students, do you consider that school dropout can increase crime? $62 \%$ of students say yes and $38 \%$ say no; in the question do you think that the factor that influences school dropout is bullying? 65\% said yes and 35\% of students said no; do you think that the insecurity of the surroundings of the institutions is a factor of desertion? $44 \%$ of the students said yes and $56 \%$ said no.

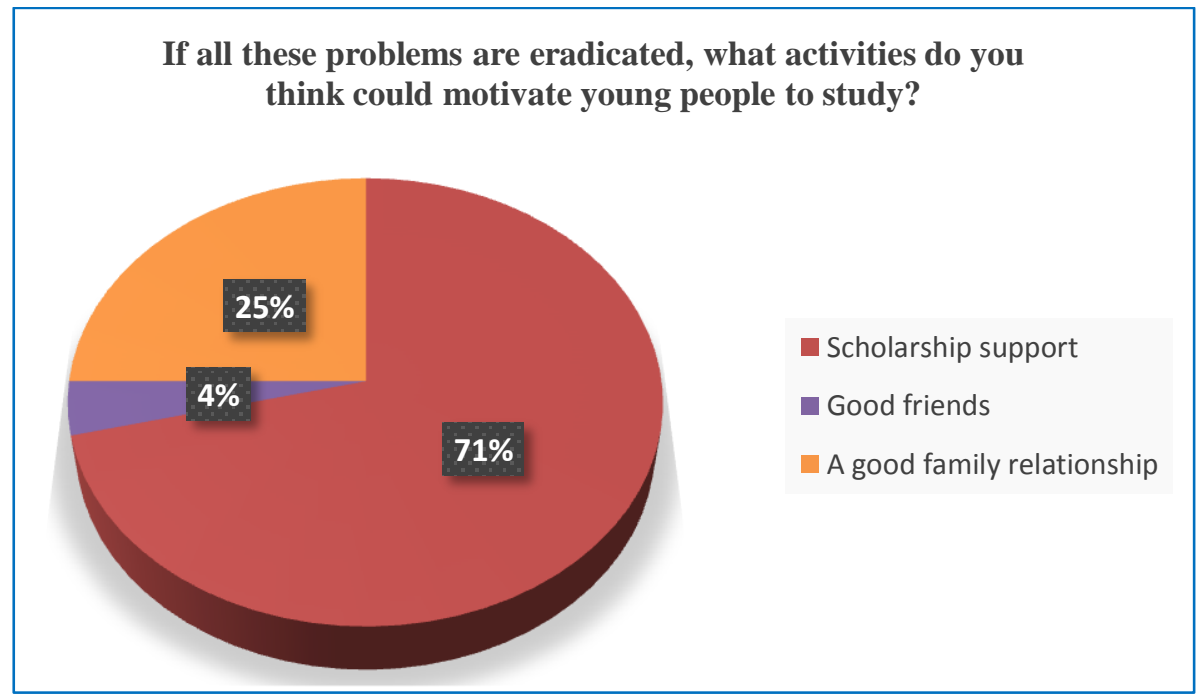

Graph 6:- If all these problems are eradicated, what activities do you think could motivate young people to study?

In graph 6, we can observe by asking students if all these problems are eradicated, what activities do you think could motivate young people to study? They answered the following, $71 \%$ supported by a scholarship, $4 \%$ considered good friendships and $25 \%$ thought a good family relationship. Higher education of the future will be a gateway to the knowledge society, perhaps the most important door because of its pre-compromised situation for the generation and transmission of human knowledge. 


\section{Conclusions:-}

According to the results, it can be concluded that the factors that influence school dropout can mention what students think the economic factor considers as a dropout factor, $62 \%$ think that crime is also another factor, $71 \%$ think that with the support of a scholarship, having good friendships and a good family relationship consider it a motivation to continue studying.

\section{References:-}

1. Aros y Quezada, A.M. (2003). Adolescence and dropout. Diploma in Public Health and family health Trends in Public Health.

2. Survey about school dropout. Available: https://es.slideshare.net/KATHERUIZ_10/encuesta-desercin-escolar

3. Flankin and Kochan (2000). Risk of dropping out. Retrieved October 14, 2019.
a. Available: sisbid.unmsm.edu.pe> BVMagazines> rpp> pdf

4. Gracia Hernández Maximiliano. (2015). University dropout in México. Available https://www.milenio.com/opinion/maximiliano-gracia-hernandez/la-economia-del-tunel/desercion-universitariaen-mexico. Retrieved October 14, 2019

5. Hernández, S.R; Fernández, C, C; Baptista, L, P. (2014). Investigation methodology. Sixth edition. Editorial Mc Graw -Hill / Interamerican. Editores, S.A. from C.V. Mexico.

6. Jiménez, D (2016) Thesis and Research. [Internet blog] Available: http://www.tesiseinvestigaciones.com/example-de-enfoque-cuantitativo-y-cualitativo/ejemplo-de-un-enfoquecuantitativo-y-un-enfoque-cualitativo [Consult 2016 / Oct. / 03]

7. Higher Education in Mexico in the 21st Century. Recovered on October 24, 2019.

a. Available.planeacion.uaemex.mx $>$ InfBasCon $>$ LaEducacionSuperiorenelSigloXXI

8. Martinez Morales Javier (2009). Review of theoretical aspects about the problem of school dropout. Available: http: www.eumed.net> rev> CED> mdaaac.

9. Román, C, Marcela (2013). Factors associated with dropping out and dropping out of school in Latin America: A look together. REICE Iberoamerican Magazine on Quality, Efficiency and Change in Education, vol. 11, no. 2. Retrieved on October 2, 2019. Available at: http://www.redalyc.org/articulo.oa?id=55127024002

10. Tinto Vicent. (1989). Define defection: a matter of perspective. Retrieved on October 1, 2018. Available: publications, anuies.mx> pdfs> magazine. 